\section{Motor Impersistence}

Irene Piryatinsky

Butler Hospital and Alpert Medical School of Brown University, Providence, RI, USA

\section{Synonyms}

Simultanapraxia

\section{Definition}

Motor impersistence is the inability to maintain postures or positions (such as keeping eyes closed, protruding the tongue, maintaining conjugate gaze steadily in a fixed direction, or making a prolonged "ah" sound) without repeated prompts. Simultanapraxia, a subset of motor impersistence, has been defined as the inability to perform more than two of the simple voluntary acts simultaneously, such as closing the eyes and protruding the tongue. According to research (Kertesz et al. 1985; Rosse and Ciolino 1986; Stuss et al. 1987), it is most likely seen in patients with right frontal damage. Joynt et al. (1962) developed a standardized objective test to measure motor impersistence.

\section{Cross-References}

Action-Intentional Disorders

- Apraxia

\section{References and Readings}

Joynt, R. J., Benton, A. L., \& Fogel, M. L. (1962). Behavioral and pathological correlates of motor impersistence. Neurology, 12, 876-881.

Kertesz, A., Nicholson, I., Cancelliere, A., Kassa, K., \& Black, S. E. (1985). Motor impersistence: A righthemisphere syndrome. Neurology, 35(5), 662-666.

Rosse, R. B., \& Ciolino, C. P. (1986). Motor impersistence mistaken for uncooperativeness in a patient with rightbrain damage. Psychosomatics, 27(7), 532-534.

Stuss, D. T., Delgado, M., \& Guzman, D. A. (1987). Verbal regulation in the control of motor impersistence: A proposed rehabilitation procedure. Neurorehabilitation and Neural Repair, 1(1), 19-24. 